\title{
Os impactos do amianto no município de Minaçu-GO
}

\author{
Elielda Aparecida Carvalho Bueno \\ Pontifícia Universidade Católica de Goiás (PUC-GO) \\ Pedro Araújo Pietrafesa \\ Mestrado em Desenvolvimento e Planejamento Territorial/ \\ Pontifícia Universidade Católica de Goiás (PUC-GO) \\ Léia Soares Bueno \\ Pontifícia Universidade Católica de Goiás (PUC-GO)
}

\begin{abstract}
Resumo
O objetivo deste artigo é analisar a dependência econômica do município de Minaçu (Goiás) da produção do amianto. Consideram-se aí os posicionamentos das autoridades municipais e dos responsáveis da mineradora SAMA. Questiona-se o "uso controlado do amianto" defendido com base em argumentos econômicos e mercadológicos a partir de diversos estudos científicos, de diferentes origens, que relacionam o amianto a males à saúde humana. A extração mineral do amianto é a principal fonte econômica do município de Minaçu, localizado na região norte do Estado de Goiás. Desde a sua criação, Minaçu desenvolveu-se em função da mina Cana Brava. Pelo artigo $2^{\circ}$ da Lei Federal N. 9.055/1995, era permitida a extração, a industrialização, a comercialização e a distribuição do amianto na variedade crisotila no país. Desde que esse dispositivo foi declarado inconstitucional pelo STF, em 29 de novembro de 2017, Minaçu vive em ambiente de incertezas quanto ao seu futuro.
\end{abstract}

Palavras-chave | Ação Direta de Inconstitucionalidade; amianto; dependência econômica; Minaçu; mineração.

Código JEL | I18 K32 L72

The impacts of asbestos production in the municipality of Minaçu-GO

\begin{abstract}
The aim of this paper is to analyze the economic dependence of the municipality of Minaçu (Goiás) on asbestos production. We consider the official positioning of the municipal authorities and of the mining company SAMA' responsible. We question the "controlled use of asbestos" - which is defended on the basis of economic and market arguments - from the perspective of various scientific studies, with origins in different parts of the world, that relate
\end{abstract}


asbestos do harm to human health. Mineral extraction of asbestos is the main economic source of the municipality of Minaçu, located in the northern region of the state of Goiás. Since it came do life, Minaçu developed as result of the mine Cana Brava. The second article of the Federal Law Number 9.055/1995 allowed the extraction, the industrialization, the commercialization and the distribution of asbestos in the chrysotile variety in Brazil. Since November 29, 2017 when that law was declared unconstitutional by the Supreme Court, Minaçu lives in an environment of uncertainties in face of it future.

Keywords | Asbestos production; Direct Action of Unconstitutionality; economic dependence; Minaçu; mining.

JEL-Code | I18 K32 L72

\section{Los impactos del asbesto en el municipio de Minaçu-GO}

\section{Resumen}

El objetivo de este artículo es analizar la dependencia económica del municipio de Minaçu (Goiás) en la producción de asbesto. Se consideran los posicionamientos de las autoridades municipales y de los responsables de la empresa minera SAMA. Se cuestiona el uso controlado de asbesto, defendido con base en argumentos económicos y mercadológicos a partir de diversos estudios científicos, de diferentes orígenes, que relacionan el asbesto a males para la salud humana. La extracción mineral de asbesto es la principal fuente económica del municipio de Minaçu, ubicado en la región norte del estado de Goiás. Desde su creación Minaçu se desarrolló en función de la mina Cana Brava. Por el artículo 2 de la Ley Federal N. 9.055/1995 era permitida la extracción, industrialización, comercialización y distribución del asbesto en la variedad de crisotilo en el país. Desde que ese dispositivo fue declarado inconstitucional por el STF, el 29 de noviembre de 2017, Minaçu vive en un ambiente de incertidumbre sobre su futuro.

Palabras clave | Acción Directa de Inconstitucionalidad; asbesto; dependencia económica; Minaçu; minería.

\section{Codigo JEL | I18 K32 L72}

\section{Introdução}

Este artigo tem como objetivo analisar a dependência econômica do município de Minaçu, localizado na Região Norte do estado de Goiás, da maior mina de amianto em atividade no Brasil, conhecida como Cana Brava, descoberta em 1962. O amianto, substância conhecida há pelo menos 3 mil anos, é largamente utilizado pela indústria devido a sua capacidade de isolamento térmico e acústico, similaridade com o cimento e resinas, resistência mecânica e flexibilidade (FIDELES; ROHLS, 2011). No Brasil, a exploração do amianto data de 1923, mas 
foi a partir da descoberta da Mina Cana Brava que deixamos de ser importadores de fibra de amianto e passamos à condição de exportadores, ocupando hoje a terceira posição na produção mundial (SILVA; ETULIAN, 2010).

Classificada como substância cancerígena pela Organização Mundial da Saúde e pela Agência Internacional de Pesquisa em Câncer (IARC), as restrições ao amianto só começaram a ser discutidas na década de 1970. Em meio ao crescimento mundial do debate sobre a substituição do amianto, surge no Brasil o movimento pelo uso controlado da substância, caracterizado na década de 1980 por ações com apoio de empresários, trabalhadores da Confederação Nacional de Trabalhadores da Indústria (CNTI) e técnicos dos governos federal e estadual. A partir da década de 1990, surge um novo grupo de interesse posicionando-se favoravelmente ao banimento do amianto, formado por sindicatos dos metalúrgicos filiados à Central Única dos Trabalhadores (CUT), empresários do setor automobilístico e técnicos do governo.

Em $1^{\circ}$ de junho de 1995 foi promulgada a Lei 9.055, que estabeleceu a posição brasileira quanto à utilização do amianto. Porém, não reduziu o embate entre os que defendem seu uso controlado e aqueles a favor do banimento. As pressões econômicas e políticas, de um lado, e a defesa da saúde do trabalhador e do meio ambiente, por outro, vão constituir os embates a que estamos assistindo há anos, com estados aprovando legislações e banindo o uso do amianto. Em 2005, a CNTI propôs uma ação direta de inconstitucionalidade em relação à Lei 3.579/2001, que tratava da substituição paulatina da produção e comércio dos produtos que contenham amianto, do estado do Rio de Janeiro, alegando invasão de competência contra o princípio da livre iniciativa.

A opção da prefeitura de Minaçu em apoiar o uso controlado do amianto, argumento defendido pelas empresas interessadas na continuidade da atividade, e a falta de alternativas econômicas para o enfrentamento da dependência da atividade mineral, provocou, após a decisão do Supremo Tribunal Federal de 29 de novembro de 2017 que proibiu o uso do amianto no Brasil, incerteza no munícipio em relação ao futuro.

Como procedimentos metodológicos utilizados para alcançar o objetivo proposto pelo artigo, foram levantados dados da arrecadação de impostos com a atividade mineral e sua representatividade na economia em Minaçu. Também foram coletadas informações acerca do conteúdo da ação de inconstitucionalidade, proposta pela Confederação Nacional dos Trabalhadores da Indústria (CNTI), dos atos decisórios mais relevantes do STF e os posicionamentos dos atores que defendem o uso controlado do amianto e daqueles a favor do banimento.

$\mathrm{O}$ artigo está dividido em cinco seções. A primeira tem caráter histórico, onde se discutem os aspectos historiográficos do uso do amianto no mundo e no Brasil. A segunda seção traz os argumentos apresentados pela coalização de atores que defendem a produção controlada de amianto no Brasil. Na terceira parte, trata-se a 
dependência econômica do município de Minaçu em relação ao setor de mineração, bem como quais alternativas são discutidas entre poder público e sociedade civil. A quarta seção aborda a discussão no Supremo Tribunal Federal e a decisão que culminou com a proibição da extração de amianto em Minaçu. Na quinta e última seção é exposta a conclusão do artigo.

\section{O uso histórico do amianto e sua produção no Brasil}

O amianto é utilizado pela humanidade desde as primeiras civilizações, porém, a expansão do seu uso na indústria ocorreu no Século XX (FIDELES; ROHLS, 2011). Em 1900, um experimento de Ludwig Hatschek revolucionou a construção civil: com uma mistura de cimento e fibras de amianto, na proporção de 10 para um, criou o fibrocimento, aumentando a produção de telhas, tubos e divisórias. Outras funcionalidades do amianto foram desenvolvidas a partir de 1929 com a construção de maquinário para a distribuição de água potável, coleta e rede de esgotos (SCLIAR, 2005).

Devido à diversidade de produtos que poderiam ser confeccionados a partir do mineral, o amianto ficou conhecido como ouro branco, "considerada a resposta rápida e eficiente na indústria, de forma geral, e na construção civil” (FILHO E LINARES, 2017, p. 655). Também conhecido como asbestos, o amianto se divide em dois grupos minerais: as serpentinas (a crisotila ou amianto branco) e os anfibólios, que se subdividem em cinco variedades: crocidolita, amosita, antofilita, actinolita e tremolita. Entre algumas de suas propriedades estão a resistência à tração comparável ao aço; baixa condutividade térmica; resistência a produtos químicos; incombustível; boa capacidade de filtragem; isolação elétrica e acústica; durabilidade; flexibilidade; afinidade com o cimento, resinas e ligantes plásticos (SILVA; E'TULIAN, 2010).

Segundo Scliar (2005), nos países desenvolvidos, além da utilização do amianto na construção civil, na produção de fibrocimento e de fricção, ele também foi largamente utilizado durante a $2^{\mathrm{a}}$ Guerra Mundial como isolante térmico em navios, trens e prédios, bem como na reconstrução de creches, escolas, hospitais, estações ferroviárias, estádios, entre outros.

No Brasil, a extração do minério teve início por volta do ano de 1923, com a descoberta da Mina de Pedra da Mesa, no município baiano de Itaberaba. Os itens derivados do amianto eram importados desde o início do século, porém, a produção e o emprego do mineral em escala industrial ocorreram em 1939 e 1940 com a chegada da Brasilit (Grupo Francês Compagnie Pont-à-Mousson) e da Eternit (Grupo Belga Compagnie Finaciêre Eternit), respectivamente (FERNANDES, 1982). 
A partir da década de 1950, a indústria emergente no Brasil aumentou significativamente as importações de amianto, que passou de 3 mil para 12 mil toneladas ao ano. Por conta do volume de minério importado, teve início uma grande procura pelas minas de amianto (SILVA; ETULIAN, 2010).

As empresas Eternit e Brasilit, para fazerem frente às mineradoras dos Estados Unidos (EUA), que estipulavam os preços internacionais por controlarem as minas canadenses, investiram em programas de pesquisas geológicas para a procura de amianto. Em abril de 1962, o garimpeiro Claudionor de Souza Alves descobriu a Mina de Cana Brava, localizada na Fazenda Maranhão, no município de Uruaçu (Goiás). Isso mudou a posição do Brasil no mercado, que passou de importador para exportador de fibras de amianto, além de garantir o abastecimento da crescente demanda interna (SCLIAR, 2005).

A Mina Cana Brava é a maior produtora de amianto em território nacional (FIDELES; ROHLS, 2011). Seus trabalhos foram iniciados em julho de 1967 com a instalação de uma usina piloto pela mineradora Sama S.A., o que permitiu ao Brasil, entre os anos de 1967 a 1985, atingir a autossuficiência na produção de amianto. Atualmente, o país ocupa a terceira posição na produção mundial, assim distribuída entre os seis maiores produtores responsáveis por $99,0 \%$ da produção mundial de crisotila (FILHO E LINARES, 2017) como podemos verificar na tabela 1.

Tabela 1 - Principais produtores mundiais de amianto em 2017

\begin{tabular}{|c|c|c|}
\hline País & Toneladas & $\begin{array}{c}\text { Participação na Produção } \\
\text { Mundial (\%) }\end{array}$ \\
\hline Rússia & 1.078 .000 & $46 \%$ \\
\hline China & 472.000 & $20 \%$ \\
\hline Brasil & 254.204 & $11 \%$ \\
\hline Cazaquistão & 240.000 & $10 \%$ \\
\hline Canadá & 183.000 & $8 \%$ \\
\hline Zimbábue & 85.000 & $4 \%$ \\
\hline
\end{tabular}

Fonte: Filho; Linares (2017, p. 656).

Em 2007, o Brasil exportou 68\% da produção nacional de amianto, atingindo 173 mil toneladas do minério, correspondendo a US\$ 63 milhões. Os principais mercados externos para os produtos brasileiros são: Índia (45,6\%), Indonésia 
$(17,1 \%)$, Tailândia $(10,3 \%)$ e México $(7,1 \%)$. Os outros destinos das exportações brasileiras são: Emirados Árabes, Colômbia, Malásia, China, Irã, África do Sul, Equador ${ }^{1}$; até 2005, também o Japão era importador de amianto brasileiro (SILVA; ETULIAN, 2010).

\section{Os interesses dos atores políticos que defendem o uso controlado do amianto no Brasil}

Classificada como substância cancerígena, pela Organização Mundial da Saúde e pela Agência Internacional de Pesquisa em Câncer (IARC), as restrições ao amianto, por provocar diversas doenças pulmonares ${ }^{2}$, só começaram a ser discutidas na década de 1970. Em 1990, inicia-se os processos de restrições à exploração e uso de amianto pelo mundo. O primeiro país proibir a exploração do amianto foi a França, e, em 2005, a União Europeia baniu o minério (SILVA; ETULIAN, 2010). Nos Estado Unidos, por volta de 1980, motivado por campanhas e denúncias contra as fibras de amianto, a substituição do produto é quase total. O consumo passou da média anual de 111 toneladas para a média anual de 33 toneladas entre 1991 e 1994 (SCLIAR, 2005).

Com o banimento do amianto pela Europa, Estados Unidos e, atualmente, mais de 50 países, e com perspectivas de rápida exaustão dos recursos minerais, a indústria do amianto deslocou-se dos países industrializados para os em desenvolvimento. Ao mesmo tempo, os desenvolvidos provocam rápida corrida tecnológica, incentivando as pesquisas para a substituição de produtos feitos a partir do mineral, por considerarem que os depósitos se encontravam em regiões politicamente instáveis (SCLIAR, 2005).

No Brasil, a mineradora Sama S.A, detentora do monopólio de extração e maior consumidora de fibra de amianto - na contramão da União Europeia e com apoio e parceria de órgãos governamentais -, tem defendido o "uso controlado do mineral", até o julgamento pelo Supremo Tribunal Federal das ações diretas de inconstitucionalidade n. 3401 e 3470.

\footnotetext{
1 Seguindo o ranking publicado em Sacramento Filho (2007, p. 6), também tendo como fonte de dados o Departamento Nacional da Produção Mineral (DNPM).

${ }^{2}$ Entre as doenças causadas pelo amianto estão a asbestose (mais frequente entre as enfermidades fatais, ocorre quando o pó de amianto se aloja nos alvéolos e compromete a capacidade respiratória, é crônica e não tem tratamento) e o câncer de pulmão (a exposição ao amianto aumenta em 10 vezes o risco da doença, sendo que o paciente sente falta de ar, emagrece e tem dor no peito). Esse tipo de câncer decorre de um tumor do tipo agressivo e costuma se espalhar pelos rins. A Mesotelioma é um câncer na membrana que envolve os pulmões (pleura). Só é causado pelo amianto, o paciente sente falta de ar e dor aguda no peito. A sobrevida após o diagnóstico é de dois anos (NASSA, 2001).
} 
Pode-se dividir os argumentos dos defensores do uso controlado do amianto em dois períodos históricos. O primeiro, em 1984, com a criação da Associação Brasileira do Amianto (Abra), cujos fundadores são Sama, Brasilit, Eternit, Asberit e Cobreq. Em 1986, a Abra promove o I Seminário Internacional sobre Exposição do Asbesto, com a publicação de 18 artigos, dos quais, 12 eram a favor do uso controlado do amianto, dois de banimento ao uso e quatro sem posicionamento. Em março de 1987, foi criado o Grupo Interestadual do Asbesto (GIA) para atuar no estado de São Paulo, entidade multiprofissional, tendo como objetivo a conscientização dos trabalhadores sobre os riscos da exposição ao amianto, bem como de preparar técnicos da área de segurança, higiene e medicina do trabalho. Como resultado desta atuação foi assinado o primeiro Acordo Nacional do Uso Controlado do Amianto no setor de fibrocimento, pela CNTI e pela Comissão Nacional do Amianto. Em 1991, acordo similar foi estendido aos trabalhadores da Mina Cana Brava, um novo acordo entre os mineiros e a Sama S.A foi assinado em 28 de setembro de 1995 (PAMPLONA, 2003).

O segundo período iniciou com a mobilização dos metalúrgicos na luta por melhorias no ambiente de trabalho. Em 1985, aconteceu a primeira fiscalização em uma indústria de lonas na cidade de São Paulo, resultado de denúncia do Sindicato dos Metalúrgicos de Osasco. Em 1991, o sindicato encaminhou um dossiê ao Ministério Público de São Paulo relatando a contaminação do amianto na Lonaflex, fabricante de lonas e pastilhas de freio, sendo realizados vários exames médicos no Serviço Social da Indústria (Sesi). Apoiados nessas denúncias, os metalúrgicos pressionaram o empresariado e, em janeiro de 1994, foi assinado acordo estabelecendo que até 31 de dezembro de 1997 haveria a substituição do amianto na indústria automobilística. Em março de 1994, foi realizado outro seminário e, ao contrário do que ocorreu em 1986, a posição predominante foi pelo banimento (PAMPLONA, 2003).

Em 1995, foi editada a Lei Federal n. 9.055 permitindo o uso controlado e responsável das fibras, inclusive do amianto, com participação ativa na aprovação pela Abra. Em 1996, a Brasilit se retira da sociedade com a empresa Sama S.A, anunciando a substituição do fibrocimento por fibra de polipropileno. Após a saída da Brasilit, surge o Instituto Brasileiro de Crisotila (IBC), responsável pela defesa do uso controlado do amianto. O (IBC) tem como parceiros: três sindicatos representados por entidades e confederações dos trabalhadores da construção civil e da indústria de Goiás, Tocantins e Distrito Federal e dos trabalhadores de extração mineral de Minaçu; 11 empresas sendo que oito delas atuam na área de telhas de fibrocimento, duas transportadoras e a mineradora Sama. Há as parcerias públicas com a Secretaria de Indústria e Comércio do Estado de Goiás (SIC), o Ministério das Minas e Energia por meio do Departamento Nacional de Produção Minera 1 (DNPM) e com a prefeitura de Minaçu. Enquanto a Abra era representada somente pelas empresas, o IBC tem na formação um conceito triparte (SCLIAR, 2005). As pressões econômicas e 
políticas com argumentos de cunhos mercadológico, econômico e social vão permear a ação da corrente defensora do uso controlado do amianto, fato este que pode ser evidenciado nos depoimentos citados a seguir.

Em entrevista para o Grupo de Trabalho da Comissão de Meio Ambiente e Desenvolvimento Sustentável da Câmara dos Deputados, criado com o objetivo de analisar as implicações do uso do amianto no Brasil. De acordo com DUARTE (2010, p.232) o presidente da Eternit ${ }^{3}$, se posicionou em relação à substituição do amianto por outras fibras e seu banimento, declarando que:

[...] não é o amianto que barateia o produto de fibrocimento; é a fibra sintética que encarece o produto de fibrocimento. É lógico que é importante entender esse raciocínio, porque, se você tem uma tecnologia diferente que custa até $60 \%$ mais caro, isso é incompatível com a proposta de fibrocimento, que a é de atender populações de baixa renda. [...] se o Brasil banir o amianto, será o primeiro país do mundo com uma reserva expressiva de crisotila puro, com potencial ainda de 37 anos, com demanda de 200 milhões de metros quadrados de telhas de fibrocimento, a abrir mão disso para ficar dependendo, como eu disse a vocês, de uma fibra cujos efeitos ninguém conhece ${ }^{4}$.

Outro argumento largamente usado em defesa do "uso controlado do amianto" é de cunho social. Cerca de $20 \%$ dos empregos gerados no município são provenientes da atividade mineral do amianto, por volta de 500 pessoas, montante confirmado pelo prefeito de Minaçu, Nick Barbosa (DEM), em entrevista à jornalista Lucia Monteiro (2017), destacando ainda, a importância econômica da atividade para o município:

O prefeito ressalta que a Sama sempre contribuiu com a administração municipal na manutenção do atendimento à saúde, asilos, creches jardinagem e até com a decoração de Natal. Já estamos perdendo toda essa ajuda. Enquanto o país precisa gerar empregos, o STF toma essa decisão.

Constata-se que argumentos econômicos e mercadológicos mereceram destaque frente aos resultados de estudos científicos em diversas partes do mundo, que vêm

\footnotetext{
${ }^{3}$ Merece destaque a mudança de estratégia da Eternit em 1976 que, avaliando o quadro mundial, cria o Programa de Nova Tecnologia e, em dois anos, inicia a produção de produtos sem amianto, com produtos petroquímicos sintéticos na Europa, permanecendo o uso do amianto somente na filial brasileira (BERMAN; HOPPE apud SCLIAR, 2005, p. 57).

${ }^{4}$ Depoimento do presidente da Eternit, Elio Martind, dado ao GT (4/12/2008, p. 233).
} 
demonstrando os males do amianto à saúde humana. Segundo Lucila, pesquisadora da Unesp:

a invisibilidade das doenças relacionadas ao amianto vem ao encontro das próprias características das doenças profissionais em geral, as quais costumam se manifestar distantes do local onde foram contraídas e, em algumas vezes, muitos anos depois, dificultando o estabelecimento de nexos causais (SCAVONE apud NASSA, 2001).

Percebe-se o viés econômico da defesa do amianto. A manutenção de uma indústria que gera milhões de dólares anualmente integra a lógica do processo de globalização hegemônica que apresenta dupla face. Trata-se de uma lógica de localismo globalizado, constituído na defesa do uso controlado, e de globalização hegemônica, na tese da defesa do banimento e da substituição da fibra de amianto por empresas transacionais (SALDANHA; BLATT, 2007)

\section{Dependência econômica de Minaçu em relação à produção de amianto}

O município de Minaçu, que em tupi-guarani significa "mina grande", possui, segundo Instituto Mauro Borges, 30.580 habitantes e está localizado no extremo norte do estado de Goiás, a $487 \mathrm{~km}$ da capital. A cidade foi povoada em 1965 após a mineradora Sama S.A obter autorização para a pesquisa da jazida de Cana Brava. Nesse contexto, Piquet (1998, p. 3) afirma que a construção de moradias junto a espaços de produção é uma prática empresarial desde o século passado, muitas cidades brasileiras surgiram neste cenário. Com o município de Minaçu não foi diferente, a Terra da Mina Grande ${ }^{5}$ surgiu e se desenvolveu em função da mineradora.

A Sama S.A ${ }^{6}$ detém a totalidade das reservas de amianto crisotila em atividade no país. As destinação e produção mundial do crisotila está com $92 \%$ aplicadas na fabricação de itens de fibrocimento, $6 \%$ na produção de fricção e $2 \%$ na indústria têxtil e outros fins.

O Imposto sobre Circulação de Mercadorias e Serviços (ICMS) e a Compensação Financeira pela Exploração de Recursos Minerais (CFEM) são os principais

\footnotetext{
5 Com o projeto de implantação de um parque industrial da Sama na região chamada Serra da Cana Brava, os moradores originais doaram uma gleba de suas terras para a implantação de um povoado, que mais tarde foi denominado Minaçu (PREFEITURA MUNICIPAL DE MINAÇU, 2017).

${ }^{6}$ Com capacidade instalada de 295 mil toneladas/ano de crisotila, mantendo-se a atual escala de produção, a vida útil da mina é estimada em 37 anos, considerando uma recuperação de 87\% das fibras no processo de beneficiamento (FILHO E LINARES, 2017, p. 664).
} 
tributos arrecadados pela mineração brasileira. O quadro 1 demonstra a destinação destes recursos temos:

\section{Quadro 1 - Destinação do ICMS e CFEM}

\begin{tabular}{|l|l|}
\hline Tributos & \multicolumn{1}{|c|}{ Destinação } \\
\hline $\begin{array}{l}\text { Imposto sobre Circulação de } \\
\text { Mercadorias e Serviços (ICMS) }\end{array}$ & $75 \%$ para os estados e 25\% para os municípios. \\
\hline $\begin{array}{l}\text { Compensação Financeira pela } \\
\text { Exploração de Recursos Minerais } \\
\text { (CFEM) }\end{array}$ & $\begin{array}{l}23 \% \text { para os estados e o Distrito Federal; 65\% para os } \\
\text { municípios; 12\% para o Departamento Nacional de } \\
\text { Produção Mineral (DNPM), que repassava 2\% à } \\
\text { proteção ambiental na região das mineradoras por } \\
\text { meio do Instituto Brasileiro de Meio Ambiente e } \\
\text { Recursos Naturais Renováveis (IBAMA). }\end{array}$ \\
\hline
\end{tabular}

Fonte: (DNPM, 2004).

A importância do amianto para a economia goiana e para o município pode ser medida pela participação do mineral na economia dos dois territórios. No período de 1972 a 2003, o amianto correspondeu a 47,59\% do produto mineral do estado, ocupando a primeira posição em relação às demais substâncias. Entre os anos de 1989 a 2003, a arrecadação com o ICMS representava uma média de recolhimento de um montante de $\mathrm{R} \$ 17$ milhões e a arrecadação com a CFEM foi de $\mathrm{R} \$ 2$ milhões (MINISTÉRIO DE MINAS E ENERGIA, 2004, p.19).

Entre o período de 1967 a 2003, a mineradora investiu cerca de R \$ 221 milhões na área de concessão de lavra, em Minaçu. Entretanto, para o triênio 2015-2017, não havia previsto nenhum investimento na área de lavra ou usina de beneficiamento, apesar das 9,8 milhões de toneladas de fibras contidas na reserva lavrável da jazida. Fato que pode ser explicado pela ação direta de inconstitucionalidade interposta pela Confederação Nacional dos Trabalhadores da Industrial (CNTI).

A partir de 2004, a participação do amianto na arrecadação da CEFEM diminui com a participação de outras substâncias como fosfato, níquel, cobre e ouro. Mesmo assim, o amianto continuou sendo a principal fonte de arrecadação do município e ficou entre as 10 substâncias que mais arrecadou CEFEM em 2016 no estado de Goiás (MINISTÉRIO DE MINAS E ENERGIA, 2017a, p.172). A Tabela 2 demonstra o total arrecadado da CEFEM com o amianto no estado entre os anos de 2004 e 2016. 
Tabela 2 - Arrecadação da CFEM com o amianto em Goiás, 2004-2016

\begin{tabular}{ccc}
\hline Ano & Arrecadação de Amianto (R\$) & Participação (\%) \\
\hline 2004 & $3.699 .650,07$ & 25,85 \\
2005 & $3.707 .440,16$ & 24,31 \\
2006 & $3.449 .324,17$ & 21,50 \\
2007 & $4.207 .774,86$ & 11,93 \\
2010 & $6.695 .081,09$ & 13,70 \\
2011 & $6.681 .889,97$ & 11,41 \\
2012 & $8.073 .751,81$ & 11,04 \\
2013 & $8.719 .109,43$ & 12,61 \\
2014 & $8.829 .213,80$ & 12,95 \\
2015 & $9.751 .110,91$ & 12,29 \\
2016 & $7.482 .236,26$ & 7,12 \\
\hline
\end{tabular}

Fonte: Ministério de Minas e Energia (2017b). Adaptado pelos autores.

A dependência de Minaçu em relação à empresa mineradora também pode ser observada na arrecadação do ICMS. Vale ressaltar que, embora existam duas hidrelétricas no município, a Serra da Mesa e a Cana Brava, 70\% da arrecadação de ICMS tem origem na atividade mineral, restando apenas $30 \%$ da arrecadação para os setores de comércio varejista, energia, prestação de serviços e outros, conforme demonstrado na Tabela 3, para o período 2007-2017.

Tabela 3 - Arrecadação de ICMS de Minaçu/atividades 2007 a 2017, R\$ mil

\begin{tabular}{ccc}
$\begin{array}{c}\text { Arrecadação por Setor de } \\
\text { Atividade }\end{array}$ & Arrecadação de ICMS (R \$Mil) & $\begin{array}{c}\text { Participação do ICMS na } \\
\text { atividade (\%) }\end{array}$ \\
\hline Comércio Varejista & 34.980 & 13 \\
Extrato Mineral ou Fóssil & 188.383 & 70 \\
Energia Elétrica & 12.986 & 5 \\
Prestação de Serviço & 26.362 & 10 \\
Outros & 4.702 & 2 \\
\hline
\end{tabular}

Fonte: IMB (2017). Adaptado pelos autores.

Quanto à geração de empregos, para a mão de obra técnica e de apoio no serviço de mineração, os empregados contratados são provenientes da região de Minaçu. Por outro lado, os trabalhadores mais especializados, são, em sua maioria, de outras regiões de Goiás, ou até provenientes de outros estados. Assim, observa-se que a empresa tem grande influência na geração de empregos. Segundo 
reportagem veiculada no Jornal O Popular, a empresa tem, em seu quadro de funcionários, entre trabalhadores diretos e prestadores de serviços, aproximadamente 500 pessoas envolvidas diretamente na atividade, representando volume significativo para uma cidade de 30 mil habitantes (MONTEIRO, 2017).

O número de empregos (lavra e beneficiamento) tem variado bastante, conforme Tabela 4. Mesmo assim, podemos observar que no período de 2007 a 2011, representava em média $22,2 \%$ do total de empregos gerados no município.

Tabela 4 - Número de empregos gerados em Minaçu e na lavra, 2007-2016

\begin{tabular}{cccc}
\hline Ano & $\begin{array}{c}\text { Total de empregos no } \\
\text { Município }\end{array}$ & $\begin{array}{c}\text { Empregos gerados na } \\
\text { mina }\end{array}$ & $\begin{array}{c}\text { Participação do } \\
\text { empregos da mina }(\%)\end{array}$ \\
\hline 2007 & 2.996 & 585 & 20 \\
2008 & 2.991 & 658 & 22 \\
2009 & 3.582 & 750 & 21 \\
2010 & 3.562 & 788 & 22 \\
2011 & 3.793 & 991 & 26 \\
2012 & 3.676 & 695 & 19 \\
2013 & 4.110 & 702 & 17 \\
2014 & 4.451 & 665 & 15 \\
2015 & 4.222 & 546 & 13 \\
2016 & 2.538 & 456 & 18 \\
\hline
\end{tabular}

Fonte: Ministério de Minas e Energia (2017a); Instituto Mauro Borges de Estatísticas e Estudos Socioeconômicos (IMB). Adaptado pelos autores.

Segundo o Ministério de Minas e energia (2017a, p. 218), no período de 2012 a 2016, a produção sofreu um decréscimo de $41,7 \%$ e a comercialização caiu $41,5 \%$, conforme a Tabela 5, influenciando na redução da geração de empregos no período mencionado.

\section{Tabela 5 - Produção e comercialização da produção mineral do amianto}

\begin{tabular}{ccc}
\hline Ano & Produção & Comercialização $(\mathrm{t})$ \\
\hline 2012 & $304.568,80$ & $303.481,25$ \\
2013 & $290.825,65$ & $295.003,24$ \\
2014 & $311.227,90$ & $248.324,55$ \\
2015 & $232.051,56$ & $248.324,55$ \\
2016 & $177.677,00$ & $177.677,00$ \\
\hline
\end{tabular}

Fonte: Ministério de Minas e Energia (2017b); base de atualização monetária: 31/12/2016. Adaptado pelos autores. 
O fato é explicado pelo movimento mundial de restrições ao amianto e pela imposição de regras com prazos definidos para seu uso, com destaque para a União Europeia, que proibiu totalmente o uso desde janeiro de 2005. Outro fator que influenciou na queda está ligado à instabilidade jurídica do mercado interno, com a ação de inconstitucionalidade proposta pela CNTI, assunto que trataremos na próxima seção.

\section{As duas ações diretas de inconstitucionalidade N. 3406 e N. 3470}

Em 2005, a CNTI propôs duas ações diretas de inconstitucionalidade, as n. 3406 e n. 3470. Em suas alegações, sustentaram que o estado do Rio de Janeiro, ao editar a Lei 3.579/2001, invadiu a alçada da União, que é quem detém competência para legislar sobre a matéria objeto da ação, além de violar o princípio da livre iniciativa, já que não existiria uma razão sustentável do ponto de vista científico (STF, 2017).

Inicialmente, a entidade de classe argumentou que a Lei 9.055/1995 é a norma geral que disciplinou a extração, a produção e o consumo do amianto no Brasil, restando ao ente estadual a possibilidade de edição de regras supletivas que versem acerca de lacunas legais ou especificidades locais próprias, o que não ocorreu no caso em exame. Haja vista que a lei estadual veda a utilização, a comercialização e a produção do amianto da variedade crisotila, indo de encontro ao estabelecido no Artigo $2^{\circ}$ da lei federal. Neste sentido, reafirma que:

A legislação estadual longe está de suplementar a Lei n. 9055/95, pois a ela faz, na realidade, flagrante contrariedade, na medida em que, nos artigos $2^{\circ}$ e $6^{\circ}$, impõe vedação à extração, produção e comercialização do amianto crisotila, cujo uso controlado é expressamente autorizado pela norma federal. Fica patente o objetivo de estabelecer normas gerais para o temo no âmbito do Estado e, o que é mais grave, em diametral objeção à lei federal, disciplinadora em larga extensão sobre todos os aspectos que se referem à CEFEM extração, produção, comércio, transporte e aproveitamento industrial do amianto.

Justifica a propositura da ação alegando que não existe fundamento científico para a vedação do uso do amianto branco, diferentemente do que ocorre com as variedades de amianto marrom e azul, dos quais a nocividade já foi comprovada. Para tanto, sustenta seu posicionamento na Convenção 162 da Organização Internacional do Trabalho que "reconhece a viabilidade técnica e científica do uso controlado das fibras de amianto crisotila" (STF, 2017a). 
A CNTI reafirma, ainda, a importância da continuidade do uso do amianto no território nacional, sob a alegação de que as indústrias brasileiras que utilizam o mineral geram cerca de 200 mil empregos diretos e indiretos, razão pela qual a aplicação da lei estadual deve ser afastada, pois, da forma em que foi editada, põe em risco a continuidade das empresas do ramo e, consequentemente, importa desemprego acentuado, com perda de sustento de um grande número de famílias (STF, 2017a).

Por fim, a Confederação Nacional dos Trabalhadores da Industria solicita a concessão de liminar para que seja suspensa a lei estadual com efeitos retroativos à época da origem dos fatos, bem como seja declarada a inconstitucionalidade de todos os dispositivos da referida norma (STF, 2017a).

No dia 29 de novembro de 2017, o Pleno do Supremo Tribunal Federal, por maioria, julgou improcedente a ação direta de inconstitucionalidade e, incidentalmente, declarou a inconstitucionalidade do Artigo $2^{\circ}$ da Lei Federal n. ${ }^{\circ}$ 9.055/95. Inconformados com o efeito da decisão, a Confederação Nacional dos Trabalhadores da Indústria (CNTI) e o Instituto Brasileiro de Crisotila (IBC) peticionaram requerendo a suspensão da eficácia da declaração de inconstitucionalidade até que o prazo para a interposição dos embargos de declaração fosse aberto, alegando que a manutenção da decisão nos moldes proferidos poderia prejudicar o exame do pedido de modulação dos efeitos, a ser interposto nos referidos embargos (STF, 2017b).

Após a decisão da relatora, a Associação Brasileira dos Expostos ao Amianto (ABREA) e a Associação Nacional dos Procuradores do Trabalho (ANPT), bem como o governador do Rio de Janeiro interpuseram agravo interno, solicitando o restabelecimento da decisão agravada nos moldes em que foi proferida no julgamento, aduzindo como fundamento que a suspensão da decisão dependeria da existência de interposição de recurso, o que não ocorreu no caso em análise, além de não ter demonstrado o risco de dano grave ou de difícil reparação (STF, 2017b).

Em decorrência dos atos processuais acima descritos, a decisão de declaração de inconstitucionalidade do Artigo $2^{\circ}$ da Lei n. 9.055/95 proferida nas ações diretas de inconstitucionalidade alcança somente o estado do Rio de Janeiro, restando suspenso o efeito erga omnes, confirmando, portanto, a constitucionalidade da Lei Estadual fluminense, já que as ações em questão discutiam a vedação do uso do amianto pela legislação estadual.

Por derradeiro, cumpre registrar que, até o momento, não foi publicado o acórdão da decisão que julgou as ações diretas de inconstitucionalidade, razão pela qual o prazo para oposição dos embargos de declaração não começou a fluir, além de estar pendente de julgamento o recurso de agravo interno. 


\section{Conclusão}

A justificativa para a continuidade do uso do amianto não pode ser fundamentada na questão financeira e no argumento de geração de empregos, cuja demissão dessa massa de trabalhadores afetará toda a economia de Minaçu. É certo que vivemos em uma sociedade eminentemente capitalista, onde todas as ações que sustentam o município, por parte da empresa, fazem, segundo Piquet (1998), parte de investimentos inseridos na lógica empresarial como estratégia competitiva no mercado internacional e instrumento das relações com a comunidade, localizada a sua volta, tornando a população defensora da empresa.

Entretanto, a Constituição Federal de 1988 estabelece ser dever do Estado adotar ações que visem à preservação da saúde dos cidadãos, garantida mediante políticas sociais e econômicas relativas à redução do risco de doenças e de outros agravos, além do acesso universal e igualitário às ações e serviços para sua promoção, proteção e recuperação.

Assim, a partir da lei maior, os municípios brasileiros deveriam assumir políticas públicas que assegurem à população bem-estar social, além de exercer um papel de promoção do desenvolvimento da região, estabelecendo uma nova relação entre município e setor privado. No entanto, o que se evidenciou em Minaçu foi uma submissão do poder municipal tanto na parte social quanto econômica, em razão de que $80 \%$ da arrecadação ser provenientes de uma única atividade econômica.

A proibição ao amianto trará, com certeza, impactos negativos sobre o município de Minaçu, mas este pode ser compensado com medidas de apoio ao desenvolvimento local de atividades alternativas, como o turismo. Acreditamos que o debate apresentado neste artigo possa estimular a discussão da transformação política que envolve os municípios e a relação entre o Estado e o setor privado.

\section{Referências}

BRASIL. Lei N. 9.055, de 01 de junho de 1995. Disciplina a extração, industrialização, utilização e transporte do asbesto/amianto e dos produtos que o contenham, bem como das fibras naturais e artificiais, de qualquer origem, utilizadas para o mesmo fim e dá outras providências. Brasília/DF: Presidência da República [1995].

Disponível

em: http://www.planalto.gov.br/ccivil_03/leis/19055.htm. Acesso em: 10 jan. 2018.

BRASIL [Constituição (1988)]. Constituição da República Federativa do Brasil. Brasília/DF: Presidência da República [2018]. Disponível em: 
www.planalto.gov.br/ccivil_03/constituicão/constituicao.htm. Acesso em: 11 jan. 2018.

DUARTE, Edson. Dossiê amianto Brasil [Relatório da Comissão de Meio Ambiente e Desenvolvimento Sustentável da Câmara de Deputados]. Brasília/DF: Câmara dos Deputados, 2010 Disponível em: http://www2.camara.leg.br/atividade-legislativa/comissoes/comissoespermanentes/cmads/gruposdetrabalho/legislatura-2007-a-2011/relatorioapresentado-pelo-relator-deputado-edson-duarte. Acesso em: 05 jan.2018.

FERNANDES, Francisco Rego Chaves. Os maiores mineradores do Brasil. CNPq/Revista Minérios, Brasília/DF, vol. 3, 1982.

FIDELES, M. L.; ROHLFS, D. B. Amianto: aspectos discursivos causais e consequentes sobre seu uso. Anais da VI Mostra de Produção Científica da Pós-Graduação Lato Sensu da PUC/Goiás. Goiânia: PUC/GO, 2011.

FILHO, Osvaldo Barbosa Ferreira; LINARES, Willian Bretas. Crisotila. Brasília: Agência Nacional de Mineração, última modificação em 14/06/17. Disponível. em:

https://sistemas.dnpm.gov.br/publicacao/mostra_imagem.asp?IDBancoArquivo Arquivo=4010Acesso em: 24 jan. 2018.

IBGE. Censo 2010. Rio de Janeiro: Instituto Brasileiro de Geografia e Estatística, 2010. Disponível em https://censo2010.ibge.gov.br. Acesso em: 14 jan. 2018.

IMB. Estatísticas municipais: séries históricas. Goiânia: Instituto Mauro Borges de Estatísticas e Estudos Socioeconômicos. Disponível em: http://www.imb.go.gov.br. Acesso em 25 jan. 2018.

MINISTÉRIO DA SAÚDE. Portaria Interministerial N. 8, de 19 de abril de 2004. Nota Técnica N. 050/2004. Disponível em: http:/ / renastonline.ensp.fiocruz.br/recursos/portaria-interministerial-ndeg-8-19abril-2004. Acesso em: 09 jan. 2018.

MINISTÉRIO DE MINAS E ENERGIA. Desempenho mineral: 37 anos de mineração em GO e DF. Brasília/DF: Departamento Nacional de Produção Mineral, 2004. Disponível em: http://www.dnpm.gov.br/dnpm/colecoes/colecao-de-publicacoes-economiamineral. Acesso em: 10 jan. 2018.

MINISTÉRIO DE MINAS E ENERGIA. Desempenho do setor mineral: 35 anos. Brasília/DF, Departamento Nacional de Produção Mineral, 2017a. 
Disponível em: http://www.dnpm.gov.br/dnpm/colecoes/colecao-depublicacoes-economia-mineral. Acesso em: 25 jan. 2018.

MINISTÉRIO DE MINAS E ENERGIA. Desempenho mineral: Seção IV, Mão-de-Obra. Brasília/DF: Departamento Nacional de Produção Mineral (anos 2008 a 2016), 2017b. Disponível em: http://www.dnpm.gov.br/dnpm/colecoes/colecao-de-publicacoes-economiamineral. Acesso em: 27 jan. 2018.

MONTEIRO, Lucia. Uma cidade com medo do futuro. O Popular. Editorial/Economia Goiânia, 12 dez. 2017. Disponível em: https://www.opopular.com.br/editorias/economia/situa $\% \mathrm{C} 3 \% \mathrm{~A} 7 \% \mathrm{C} 3 \% \mathrm{~A} 3 \mathrm{O}-$ \%C3\%A9-de-desespero-diz-prefeito-1.1325130. Acesso em: 28 dez. 2017.

NASSA, Thiago. O fantasma do amianto: um mal invisível. Boletim Informativo UNESP, Edição 03 dez. 2001. Disponível em: http://www.unesp.br/proex/informativo/edicao03dez2001/materias/amianto.ht m.Acesso em: 05 jan. 2018.

PAMPLONA, Renato Ivo. O amianto crisotila e a Sama: 40 anos de história Minaçu-Goiás (da descoberta à tecnologia limpa: 1962-2002). Minaçú/GO: R. I. Pamplona, 2003.

PIQUET, Rosélia. Cidade-Empresa: presença na paisagem urbana brasileira. Rio de Janeiro: Jorge Zahar Editor, 1998.

PREFEITURA MUNICIPAL DE MINAÇU. História, 2017. Disponível em: http://www.minacu.go.gov.br/pagina/152-historia. Acesso em: 12 de fev. 2018.

RIO DE JANEIRO. Lei N. 3.579, de 07 de junho de 2001. Dispõe sobre a substituição progressiva da produção e da comercialização de produtos que contenham asbesto e dá outras providências. Rio de Janeiro: Assembleia Legislativa 2001. Disponível em: www.secovirio.com.br/.../Lei-Estadual-3579-01--Substituição-Progressiva-de-Amianto. Acesso em: 10 jan. 2018.

SALDANHA, Jânia Lopes; BLATT, Paulo Roberto. O caso amianto: conjuntura internacional e jurisprudência do STF. Revista Eletrônica do Curso de Direito da UFSM, vol. 2, n. 3, 2007. Disponível em: https://periodicos.ufsm.br/revistadireito/article/view/6816. Acesso em: 26 jan. 2018.

SCLIAR, Claudio. Amianto: mineral mágico ou maldito? Ecologia humana e disputa político-econômica. 5 ed. Belo Horizonte: Novatus, 2005. 
SILVA, A. L. G.; ETULAIN, C. R. Avaliação do impacto econômico da proibição do uso do amianto na construção civil no Brasil (= Relatório Final de Pesquisa). Campinas: Unicamp, 2010.

SUPREMO TRIBUNAL FEDERAL (STF). Ação Direta de Inconstitucionalidade 3.470. Brasília/DF, 2017a. Disponível em: http://redir.stf.jus.br/paginadorpub/paginador.jsp?docTP=TP\&docID=7490205 01. Acesso em: 30 jan. 2018.

SUPREMO TRIBUNAL FEDERAL (STF). STF reafirma inconstitucionalidade de dispositivo que permitia extração de amianto crisotila. Notícias STF. Brasília/DF, 29 nov. 2017b. Disponível em: http://www.stf.jus.br/portal/cms/verNoticiaDetalhe.asp?idConteudo=363263. Acesso em: 10 fev. 2018.

Endereço para correspondência:

Elielda Aparecida Carvalho Bueno - elieldabueno@gmail.com

Avenida Universitária, 1440 - Setor Universitário

74605-010 Goiânia/GO, Brasil

Pedro_Araíjo Pietrafesa - pedro_pietrafesa@yahoo.com.br

Avenida Universitária, 1440 - Setor Universitário

74605-010 Goiânia/GO, Brasil

Léia SoaresBueno - buenoleia@hotmail.com

Avenida Universitária, 1440 - Setor Universitário

74605-010 Goiânia/GO, Brasil 